\title{
Edible Oxya chinensis sinuosa-Derived Protein as a Potential Nutraceutical for Anticancer Immunity Improvement
}

\author{
Woo Sik Kim ${ }^{1,+}$, Jeong Moo Han ${ }^{1,2,+}$, Ha-Yeon Song ${ }^{1,2}$, Eui-Hong Byun ${ }^{3}$, Ho Seong Seo ${ }^{1}$ and \\ Eui-Baek Byun 1,* \\ 1 Advanced Radiation Technology Institute, Korea Atomic Energy Research Institute, Jeongeup 580-185, \\ Korea; kws6144@kaeri.re.kr (W.S.K.); jmhahn@kaeri.re.kr (J.M.H.); songhy@kaeri.re.kr (H.-Y.S.); \\ hoseongseo@kaeri.re.kr (H.S.S.) \\ 2 Department of Biotechnology, College of Life Science and Biotechnology, Korea University, \\ Seoul 136-701, Korea \\ 3 Department of Food Science and Technology, Kongju National University, Yesan 340-800, Korea; \\ ehbyun80@kongju.ac.kr \\ * Correspondence: ebbyun80@kaeri.re.kr; Tel.: +82-063-570-3245 \\ + These authors contributed equally to this work.
}

Received: 14 September 2020; Accepted: 21 October 2020; Published: 22 October 2020

\begin{abstract}
Oxya chinensis sinuosa (Ocs) is consumed as representative edible insects in Asia, but its function in various immune systems remains unclear. This study aimed to demonstrate the immunomodulatory effect, particularly on the innate and adaptive immune response, of Ocs protein (Ocs-P) and to investigate its function as a potent anticancer immunostimulant when administered during the progression stage of colon carcinoma in tumor-bearing mice. Our in vitro results demonstrated that Ocs-P treatment induces phenotypic alteration (increased expression of surface molecules and production of T Helper type I-polarizing (Th1-polarizing) cytokines and decreased antigen uptake ability) of dendritic cells (DCs) through the activation of Mitogen-activated protein kinase (MAPK) and nuclear factor kappa B-dependent (NF- $\mathrm{B}$-dependent) signaling pathways. Additionally, Ocs-P-stimulated DCs initiated differentiation of naive $\mathrm{T}$ cells into IFN- $\gamma$-producing Th1-type T cells effectively and activated cytotoxic CD8 ${ }^{+} \mathrm{T}$ cell response. In colon carcinoma-bearing mouse models, oral administration of Ocs-P inhibited tumor growth and restored the expression of decreased surface molecules in lineage $\mathrm{CD}^{-} 11 \mathrm{c}^{+} \mathrm{MHC}-\mathrm{II}^{+}$splenic DCs. Furthermore, Ocs-P administration enhanced the generation of multifunctional CD4 ${ }^{+}$and CD8 ${ }^{+} \mathrm{T}$ cells expressing Th1-type cytokines (TNF- $\alpha$, IFN- $\gamma$, and IL-2) and the degranulation marker (CD107a). Collectively, these results suggest that Ocs-P demonstrates an immunostimulatory effect and may induce powerful anticancer immunity.
\end{abstract}

Keywords: dendritic cells; Oxya chinensis sinuosa; protein; Th1; cytotoxic T cells; multifunctional T cells

\section{Introduction}

Insects have received attention for multiple purposes, not only as food and feed sources but also as living creatures that provide a variety of beneficial substances [1]. This considerable attention on insects originated from their advantages of being abundant and environmentally friendly; they constitute more than $80 \%$ of all living organisms on the earth and require less land and water in comparison with livestock [2-4]. Notably, insects have advantages regarding nutritional value; particularly, insects have high-quality proteins and are composed of $50 \%-70 \%$ total protein compared with plant and meat 
proteins [5-8]. Incidentally, insects have great potential to become one of the most promising protein sources, owing to their ability to solve the global problem of protein production regarding nutrition, environment, and economic value [7,9]. Apart from their nutritional roles, insect proteins have various pharmacological properties, such as antioxidant activity, anticancer activity, and a protective effect against atherosclerosis [10-13]. Water-soluble proteins derived from grasshoppers have strong antioxidant activities [14]. In addition, protein isolated from Aspongopus chinensis inhibits cancer cell proliferation by inducing apoptosis acceleration [15].

Oxya chinensis sinuosa (Ocs) is a grasshopper species belonging to the phylum Arthropoda (order, 54 Orthoptera; family, Acrididae; subfamily, Oxyinae), and the order Orthoptera contains the fourth most consumed edible insects, worldwide [1,14]. Traditionally in Korea, Ocs has been used as a remedy to cough, whooping cough, asthma, bronchitis, seizures, and paralysis [16]. Recently, the Korea Food \& Drug Administration registered Ocs as a food in the Korean Food Standards Codex. Notably, Ocs proteins (Ocs-Ps) have been reported to enhance antioxidant, antimicrobial, and antiplatelet aggregation activities $[10,14,17]$. However, the immunological actions of Ocs-P, particularly on the innate and adaptive immune response, have not been fully investigated. A clearer immunological understanding of natural products may lead to the design of more successful nutraceuticals or functional materials; thus, there is an urgent need to better understand the immunological functions of Ocs-P. These studies could help provide a better understanding of its immunological effects on the use as edible insect.

Here, we investigated the immunomodulatory effect of Ocs-P in innate and adaptive immunity on the basis of dendritic cells (DCs), which are critical for initiating the adaptive immune response [18], and explored the major mechanisms controlling DC maturation. Additionally, immunological functions of Ocs-P as a potent immunostimulator that induces strong anticancer immunity were investigated.

\section{Materials and Methods}

\subsection{Animal Studies}

Bone marrow-derived dendritic cell (BMDC) differentiation and in vivo experiments were performed using 7- to 8-week-old C57BL/6 and BALB/c female mice from Orient Bio Inc. (Seoul, Korea). All animal studies were performed in accordance with the established guidelines of Korea Atomic Energy Research Institute (KAERI, Jeongeup, Korea) and approved by the Institutional Animal Care and Use Committee (IACUC) of KAERI (permit number: KAERI-IACUC-2019-001).

\subsection{Antibodies and Reagents}

For BMDC differentiation, primary cell culture was performed using recombinant mouse (rm)-granulocyte-macrophage colony-stimulating factor (rm-GM-CSF) and rm-interleukin-4 (rm-IL-4) from JW CreaGene (Daegu, Korea). As a positive control for in vitro BMDC maturation, ultrapure lipopolysaccharide (LPS) from Escherichia coli serotype 0111:B4 (Invivogen, San Diego, CA, USA) was used. For cytotoxic analysis, Annexin $\mathrm{V}$ and propidium iodide (PI) antibodies (Abs) were obtained from BD Bioscience (San Jose, CA, USA). The analysis of maturation, activation, and phenotypic alteration of DCs and T cells were performed via flow cytometry (FACSverse, BD Bioscience) using the following fluorescence-conjugated Abs: Live/Dead Cell Staining Kit (L/D; BV510) from Invitrogen (Carlsbad, CA, USA); Cell Proliferation Dye (CPD) eFluor 450, anti-major histocompatibility complex class I (-MHC-I; APC), -MHC-II (PE-Cy7), -cluster of differentiation 3 (CD3; APC-Cy7), -CD4 (Alexa488), -CD8 $\alpha$ (Percp-Cy5.5), -IFN- $\gamma$ (PE), -TNF- $\alpha$ (APC), and -IL-2 (PE-Cy7) Abs from eBioscience (San Diego, CA, USA); anti-CD11c (PE-Cy7), -CD80 (FITC), -CD86 (PE), -TNF- $\alpha$ (APC), -IL-12p70 (PE), -IL-10 (FITC), -CD107a (V450), -F4/80 (BV421), -B220 (BV421), -NK1.1 (BV421), -CD3e (BV421), and -Gr-1 (BV421) Abs from BD Bioscience. Analysis of isotype controls for DC surface molecule expression was performed using corresponding appropriate isotype Abs for surface molecules: rat IgG2 kappa (FITC), rat IgG2a kappa (PE), rat IgG2a kappa (APC), and rat IgG2b kappa (PE-Cy7) from BD Bioscience. Extracellular 
cytokine analysis was performed through enzyme-linked immunosorbent assay (ELISA) using the following mouse-specific ELISA kits: TNF- $\alpha$, IL-12p70, IL-10, IFN- $\gamma$, IL-5, and IL-2 ELISA kits from BD Bioscience. Analysis of antigen (Ag) uptake ability was performed using FITC-conjugated 40,000 Da dextran (Sigma, St. Louis, MO, USA). Analysis of MAPK and NF-kB signals was performed using the following immunoblotting mouse Abs (mAbs) and signaling pathway-specific pharmacological inhibitors: phosphorylated ( $p$ )-extracellular-signal-regulated kinase (p-ERK), p-c-Jun N-terminal kinase (p-JNK), p-p38, p-inhibitor kappa B-alpha (p-IkB- $\alpha$ ), total-ERK, total-JNK, total-p38, IkB- $\alpha$, NF-kB, lamin B, and $\beta$-actin from Cell Signaling Technology (Boston, MA, USA); U0126 (ERK), SP600125 (JNK), SB203580 (p38), and Bay11-7082 (NF-kB) from Calbiochem (San Diego, CA, USA). Isolation of naive $\mathrm{CD}^{+}$and $\mathrm{CD}^{+}{ }^{+} \mathrm{T}$ cells was performed with MACS MicroBeads system using $\mathrm{CD} 4^{+}$and $\mathrm{CD} 8^{+}$isolation kits (Miltenyi Biotec, San Diegom, CA, USA).

\subsection{Isolation of Ocs-P Extract}

Dried Ocs (100 g, Sworm Co., Seoul, Korea) was ground for 1 min using a manual grinder; the dried powder was mixed with $600 \mathrm{~mL}$ demineralized water containing $0.16 \%$ ascorbic acid, and this was subsequently incubated at $4{ }^{\circ} \mathrm{C}$ for $1 \mathrm{~h}$. Following incubation, samples were ground again for $1 \mathrm{~min}$, and the obtained solutions were centrifuged for $30 \mathrm{~min}$ at 70,000 rpm. Collected supernatants were filtered through Whatman No. 4 filter paper (Florham Park, NJ, USA) to remove the debris. Filtered solutions were dried in a vacuum freeze drier (VD-800F; Taitec, Saitama-ken, Japan), and freeze-dried powders (percentage yield of Ocs-P: $3.81 \%$ ) were resuspended in phosphate-buffered saline (PBS, Biowest, Nuaille, France) and filtered through a $0.45 \mu \mathrm{m}$ filter (Corning, NY, USA). Finally, we confirmed the absence of endotoxin or LPS contamination of purified Ocs-P using the Limulus Amebocyte Lysate (LAL) assay (Lonza, Basel Switzerland), following the manufacturer's instructions.

\subsection{Treatment Conditions of Ocs-P in BMDCs}

Differentiation of BMDCs isolated from C57BL/6 mice were prepared as previously described [19]. Briefly, bone marrow cells were incubated for $8 \mathrm{~d}$ in the presence of RPMI-1640 medium (Biowest) supplemented with $10 \%$ heat-inactivated fetal bovine serum (FBS, Biowest), $1 \%$ penicillin/streptomycin (P/S, GIBCO, Carlsbad, CA, USA), 20 ng/mL GM-CSF, and $0.5 \mathrm{ng} / \mathrm{mL}$ IL-4. Thereafter, cells were harvested and conformed for BMDC purity (>90\% purity) by FACSverse using anti-CD11c Ab. For Ocs-P treatment, BMDCs $\left(1 \times 10^{6} /\right.$ well in a 48 -well plate) were stimulated with varying doses ( 1 to $100 \mu \mathrm{g} / \mathrm{mL}$ ) of Ocs-P and incubated for $20 \mathrm{~h}$ at $37^{\circ} \mathrm{C} / 5 \% \mathrm{CO}_{2}$. As a positive control for DC maturation, BMDCs were treated with $100 \mathrm{ng} / \mathrm{mL}$ LPS under Ocs-P-stimulated conditions.

\subsection{Annexin $V$ and PI Staining}

Non-, LPS-, and Ocs-P-treated BMDCs (treated for $20 \mathrm{~h}$ ) were harvested and stained with Annexin $\mathrm{V}$ and PI, according to the manufacturer's protocol. Necrotic, late apoptotic, and apoptotic cell deaths were evaluated by detecting double or single positive cells of Annexin V and PI using FACSverse and FlowJo software (V10, BD Bioscience).

\subsection{Analysis of Surface Molecules of BMDC}

BMDCs (treated for $20 \mathrm{~h}$ ) were stained with L/D, anti-CD80, -CD86, -MHC-I, and MHC-II Abs for $20 \mathrm{~min}$ at room temperature, washed with cold FACS washing buffer ( $2 \%$ FBS and $0.01 \%$ sodium azide in PBS), and finally fixed in IC fixation buffer (eBioscience). The surface expression levels of BMDCs were assessed using FACSverse and FlowJo software.

\subsection{Detection of Intracelluar and Extracelluar Cytokines in BMDCs}

For extracellular cytokine analysis, culture supernatants (treated for $20 \mathrm{~h}$ ) of non-, LPS-, and Ocs-P-treated BMDCs were harvested, and TNF- $\alpha$, IL-12p70, and IL-10 levels were measured 
with the respective ELISA kits, according to the manufacturers' protocols. For intracellular cytokine analysis, BMDCs were treated with LPS and Ocs-P in the presence of GolgiPlug (BD Bioscience) for $8 \mathrm{~h}$, and stimulated cells were subsequently collected and washed twice with cold FACS washing buffer. Thereafter, harvested cells were stained with anti-CD11c Ab for $20 \mathrm{~min}$ at room temperature and washed twice with cold FACS washing buffer. Cells were fixed and permeabilized using BD Cytofix/Cytoperm buffer for $20 \mathrm{~min}$ at room temperature and washed twice with BD Perm/Wash buffer. Following washing, cells were stained with anti-TNF- $\alpha$, -IL-12p70, and -IL-10 Abs. Finally, cells were washed twice with BD Perm/Wash buffer, and intracellular cytokine levels in BMDCs (CD11c ${ }^{+}$cells) were assessed using FACSverse and FlowJo software.

\subsection{Analysis of Ag Uptake Ability in BMDCs}

Non-, LPS-, and Ocs-P-treated BMDCs (treated for $20 \mathrm{~h}$ ) were incubated with $1 \mathrm{mg} / \mathrm{mL}$ dextran for $40 \mathrm{~min}$ at $37^{\circ} \mathrm{C}$ and $4{ }^{\circ} \mathrm{C}$. Cells were washed three times with cold FACS washing buffer and stained with anti-CD11c Ab for $30 \mathrm{~min}$ at $4{ }^{\circ} \mathrm{C}$. Thereafter, cells were washed and fixed with IC fixation buffer, and the uptake levels $\left(\mathrm{CD} 11 \mathrm{c}^{+}\right.$Dextran $^{+}$cells) of dextran in BMDCs were assessed using FACSverse and FlowJo software.

\subsection{Western Blotting Analysis}

Cytosolic and nuclear proteins were isolated by cell lysis with the Pierce RIPA buffer (Rockford, IL, USA) and the CelLytic NuCLEAR Extraction Kit (Sigma), respectively. The subsequent steps were performed as described previously [20].

\subsection{Ocs-P-treated BMDC Maturation Induced by Inhibition of the MAPK and NF-kB Signaling Pathways}

BMDCs were pretreated with each MAPK (U0126; $10 \mu \mathrm{M}, \mathrm{SP600125;} 20 \mu \mathrm{M}, \mathrm{SB} 20358 ; 20 \mu \mathrm{M}$ ), and NF-kB (Bay11-7082; $10 \mu \mathrm{M}$ ) signaling inhibitor for $2 \mathrm{~h}$ prior to Ocs-P stimulation for $20 \mathrm{~h}$. Thereafter, the ELISA was used to measure extracellular cytokine levels (TNF- $\alpha$ and IL-12p70) in the cell culture supernatants. Additionally, cells were analyzed for surface molecules (CD80, CD86, MHC-I and MHC-II) of DCs using FACSverse.

\subsection{Allogenic Mixed Lymphocyte Reaction}

Splenic $\mathrm{CD} 4^{+}$and $\mathrm{CD} 8^{+} \mathrm{T}$ cells from BALB/c mice were isolated using MACS CD4 ${ }^{+}$and $\mathrm{CD} 8^{+}$ isolation kits. Isolated T cells were incubated with $1 \mu \mathrm{M}$ Cell Proliferation Dye (CPD) eFluor 450 in a $37^{\circ} \mathrm{C}$ water bath under dark conditions. Following 15 min of staining, cells were washed three times with cold PBS containing 10\% FBS. Thereafter, CPD-labeled T cells $\left(5 \times 10^{5} /\right.$ well in a 96-well plate) were co-cultured with non-, LPS-, and Ocs-P-treated BMDCs $\left(1 \times 10^{5} /\right.$ well in a 96-well plate $)$ in the presence of RPMI-1640 medium containing 10\% FBS and 1\% P/S. Following $3 \mathrm{~d}$ of culturing, extracellular cytokine levels (IFN- $\gamma$, IL-5, and IL-2) were measured in the cell culture supernatants using ELISA. Thereafter, each $\mathrm{CD} 4^{+}$and $\mathrm{CD} 8^{+} \mathrm{T}$ cell was harvested and washed twice with cold FACS washing buffer. Harvested $\mathrm{CD} 4^{+}$and $\mathrm{CD} 8^{+} \mathrm{T}$ cells were subsequently stained with anti-CD4 and -CD8 Abs, respectively. Finally, cells were washed twice with cold FACS washing buffer and fixed with IC fixation buffer, and proliferation levels (percentage of CPD-negative T cells) of $\mathrm{CD}^{+}$and $\mathrm{CD}^{+} \mathrm{T}$ cells were assessed using FACSverse and FlowJo software.

\subsection{Cytotoxic T Lymphocyte (CTL) Function Assay}

BMDCs were stimulated with Ocs-P $(100 \mu \mathrm{g} / \mathrm{mL})$ in the absence and presence of $1 \mu \mathrm{g} / \mathrm{mL}$ Ovalbumin $_{257-264}\left(\mathrm{OVA}_{257-264}\right)$ peptide (SIINFEKL, AbFrontier, Seoul, Korea) bound to H-2Kb of MHC-I. Following a $20 \mathrm{~h}$ treatment, cells were harvested and washed twice with cold PBS. Thereafter, C57BL/6 mice were immunized intravenously three times (on days 1, 3, and 5) with PBS (PBS-injected group $)$ or each DC $\left(2 \times 10^{6} /\right.$ mouse; non-treated DC, $\mathrm{OVA}_{257-264}$-treated DC, and DC treated with 
$\mathrm{OVA}_{257-264}$ and Ocs-P). After $5 \mathrm{~d}$ of the last immunization, naive splenic $\mathrm{T}$ cells were prepared from C57BL/6 mice, incubated in the presence and absence of $\mathrm{OVA}_{257-264}$ peptide for $2 \mathrm{~h}$, harvested, and washed twice with cold PBS. Among these samples, $\mathrm{OVA}_{257-264}$-treated T cells were stained with a high-dose Cell Proliferation Dye (CPD, $5 \mathrm{mM})$ in a $37^{\circ} \mathrm{C}$ water bath under dark conditions for $15 \mathrm{~min}$. In contrast, non-treated T cells were stained with low-dose CPD $(0.5 \mathrm{mM})$. Thereafter, $\mathrm{CPD}^{\text {high }}$-stained $\mathrm{OVA}_{257-264}$-treated T cells $\left(5 \times 10^{6} /\right.$ mouse $)$ and $\mathrm{CPD}^{\text {low }}$-stained non-treated T cells $\left(5 \times 10^{6} / \mathrm{mouse}\right)$ were mixed together at 1:1 ratio and were intravenously injected into PBS- and DC-immunized C57BL/6 mice. After $6 \mathrm{~h}$, mice were sacrificed, and spleen cells were isolated from each group. Finally, cytotoxic activity via decreased levels of $C P D^{\text {high }}$-stained $\mathrm{T}$ cells from each spleen cell was assessed using FACSverse and FlowJo software.

\subsection{Animal Experiment for Antitumor Effect}

The mouse colon carcinoma cell line CT26 (purchased from the American Type Culture Collection) used in in vivo experiments was maintained at $37^{\circ} \mathrm{C} / 5 \% \mathrm{CO}_{2}$ in the presence of RPMI-1640 medium containing $10 \% \mathrm{FBS}$ and $1 \% \mathrm{P} / \mathrm{S}$; six passages of cells were performed for in vivo antitumor experiments. These cells $\left(1 \times 10^{5} /\right.$ mouse $)$ were subsequently washed and inoculated subcutaneously into naive $\mathrm{BALB} / \mathrm{c}$ mice. At $6 \mathrm{~d}$ after tumor inoculation, mice were orally administered with Ocs-P (10 mg/mouse) five times at $3 \mathrm{~d}$ intervals, and tumor size was calculated seven times every $3 \mathrm{~d}$ using the formula: area $=\left(\right.$ length $\times$ wideth $\left.^{2}\right) / 2$.

For analysis of splenic DC maturation induced by Ocs-P administration, $24 \mathrm{~d}$ after tumor inoculation, mice were sacrificed, and single-cell suspensions of spleens were isolated. These were stained with L/D, lineage cocktail (anti-Gr-1 Ab; neutrophil marker, anti-F4/80 Ab; macrophage marker, anti-B220 Ab; B cell marker, anti-NK1.1 Ab; NK cell marker, and anti-CD3e Ab; T cell marker), anti-CD11C, -CD80, -CD86, -MHC-I, and -MHC-II Abs for $30 \mathrm{~min}$ at $4{ }^{\circ} \mathrm{C}$. Cells were washed twice with cold FACS washing buffer and then fixed. Expression levels of surface molecules in splenic DCs $\left(\mathrm{L} / \mathrm{D}^{-}\right.$lineage $\left.\mathrm{C}^{-} \mathrm{CD} 11 \mathrm{c}^{+} \mathrm{MHC}-\mathrm{II}^{+}\right)$were evaluated using FACSverse and FlowJo software.

For analysis of multifunctional $\mathrm{CD} 4^{+}$and $\mathrm{CD} 8^{+} \mathrm{T}$ cell responses induced by Ocs-P administration, $24 \mathrm{~d}$ after tumor inoculation, mice were sacrificed, and splenic $\mathrm{T}$ cells were isolated. Splenic $\mathrm{T}$ cells $\left(1 \times 10^{6} / \mathrm{mL}\right)$ were stimulated with $1 \times$ eBioscience Cell Stimulation Cocktail (plus protein transport inhibitor) in the presence of anti-CD107a Ab for $4 \mathrm{~h}$ at $37^{\circ} \mathrm{C} / 5 \% \mathrm{CO}_{2}$. Stimulated cells were washed twice with cold FACS washing buffer and stained with L/D, anti-CD3,-CD4, and -CD8 Abs for $30 \mathrm{~min}$ at $4{ }^{\circ} \mathrm{C}$. Thereafter, cells were washed twice with cold FACS washing buffer, fixed and permeabilized using BD Cytofix/Cytoperm buffer for $20 \mathrm{~min}$ at room temperature, and washed twice with BD Perm/Wash buffer. Thereafter, cells were stained anti-IFN- $\gamma,-$ IL-2, and -TNF- $\alpha$ Abs. Finally, cells were washed twice with BD Perm/Wash buffer, and intracellular cytokine and CD107a levels in $\mathrm{CD} 4^{+}\left(\mathrm{L} / \mathrm{D}^{-} \mathrm{CD} 3^{+} \mathrm{CD} 4^{+}\right)$ and $\mathrm{CD} 8^{+}\left(\mathrm{L} / \mathrm{D}^{-} \mathrm{CD} 3^{+} \mathrm{CD} 8^{+}\right) \mathrm{T}$ cells were assessed using FACSverse and FlowJo software.

\subsection{Statistical Analysis}

Data were assessed using Tukey's unpaired t-tests or multiple comparison tests with GraphPad Prism 7 (2018, GraphPad, San Diego, CA, USA). Data are represented as the mean \pm standard deviation (SD). ${ }^{*} p<0.05,{ }^{* *} p<0.01$, and ${ }^{* * *} p<0.001$ were considered statistically significant.

\section{Results}

3.1. Ocs-P Promotes a Typical Maturation Profile for Potential Th1 Polarization and Cytotoxic CD8 $8^{+} T$ Cell Responses in Primary BMDCs

Th1 and CTL responses play a major role in protecting and eliminating tumor progression [21]. Notably, activation, proliferation, and differentiation of these T cells require the Th1-polarizing cytokines (TNF- $\alpha$ and IL-12p70) predominantly produced by Ag presenting cells (APCs; macrophages and DCs) and the interactions of APCs and T cells by upregulating surface molecules (CD80, CD86, MHC-I, 
and MHC-II) on APCs [22-25]. Thus, we confirmed whether Ocs-P could induce DC maturation with production of Th1-polarizing cytokines and upregulation of surface molecules. Prior to this, the cytotoxic effect of Ocs-P in various concentrations was described in BMDCs, as cytotoxicity can affect DC maturation. Therefore, $\leq 100 \mu \mathrm{g} / \mathrm{mL}$ Ocs-P treatment of BMDCs demonstrated no significant increase in Annexin $\mathrm{V}^{+}$and/or $\mathrm{PI}^{+}$cells (Figure 1A). Thus, in vitro experiments for DC maturation were conducted. Thereafter, we analyzed the expression of various surface molecules in LPS (positive control for DC maturation)- and Ocs-P (1 to $100 \mu \mathrm{g} / \mathrm{mL}$ )-treated BMDCs. As shown in Figure 1B, expression levels (percentage and MFI value) of CD80, CD86, MHC-I, and MHC-II of BMDCs significantly increased in a dose-dependent manner by Ocs-P treatment.

A
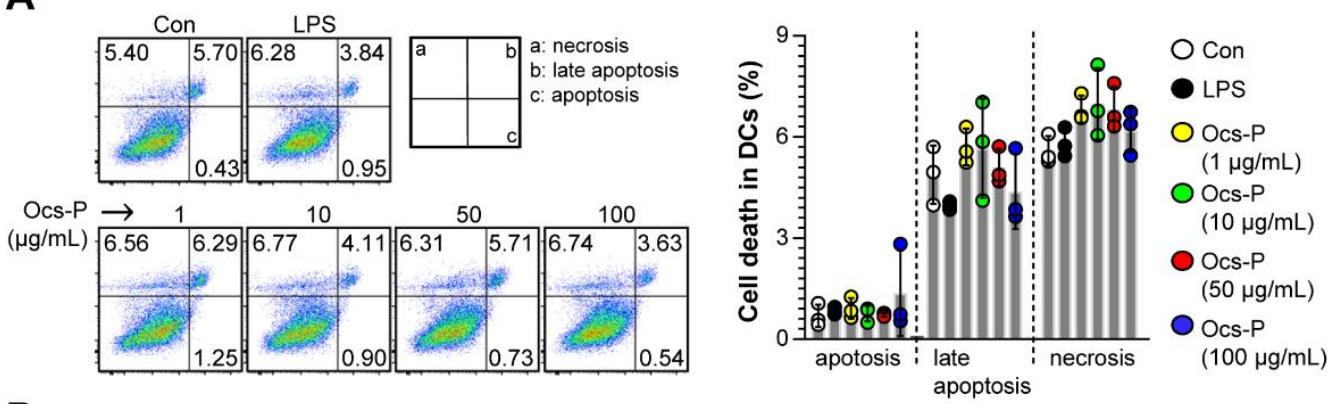

B
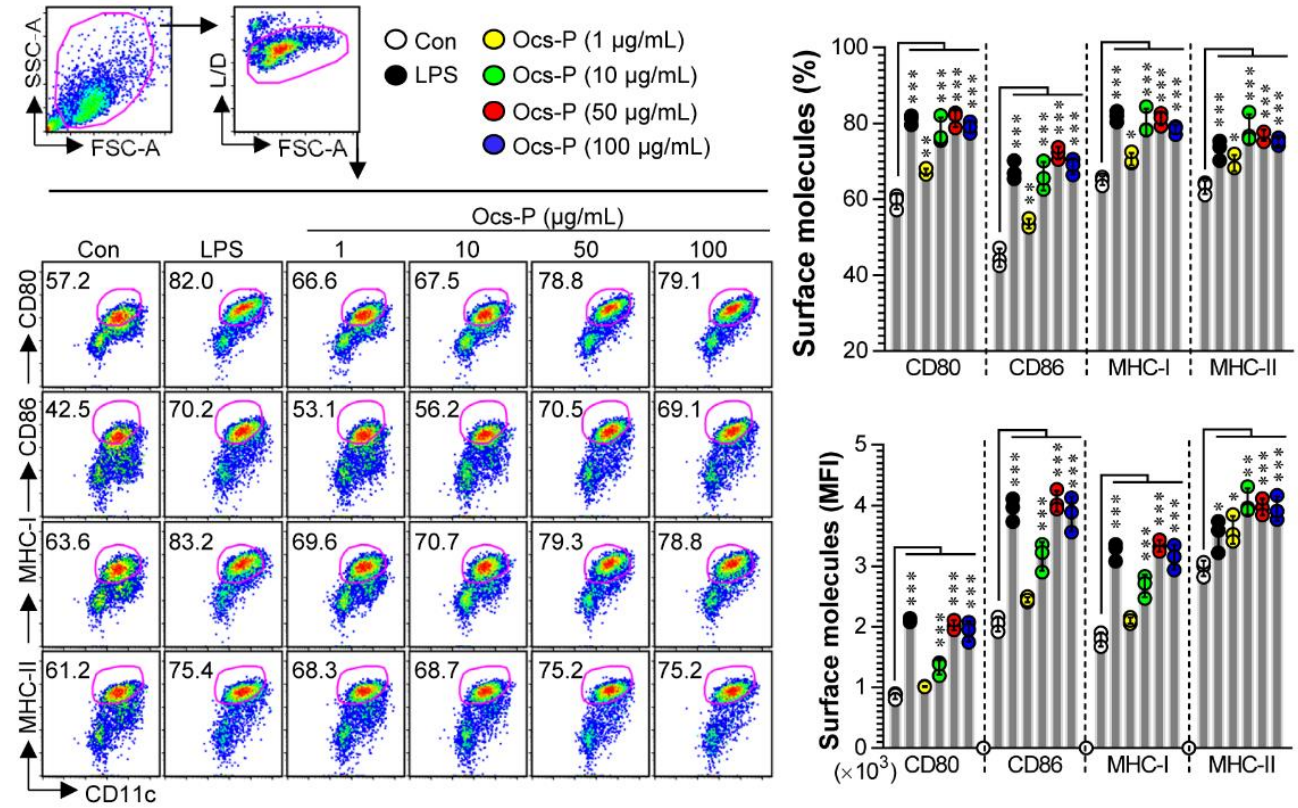

Figure 1. Cytotoxicity and phenotype characteristics induced by Ocs-P treatment in in vitro cultured BMDCs. (A) Immature BMDCs were subjected to LPS (100 ng/mL) or Ocs-P (1 to $100 \mu \mathrm{g} / \mathrm{mL})$ treatment for $20 \mathrm{~h}$ or no treatment (Con), and dead cells (necrotic, late apoptotic, apoptotic cell death) were measured by Annexin V and PI staining; (B) Non- (Con), LPS-, and Ocs-P-treated DCs were stained with surface antibodies (anti-cluster of differentiation 80 (anti-CD80), -CD86, -major histocompatibility complex class I (-MHC-I), and -MHC-II) and pan-DC marker (anti-CD11c), and the expression levels (percentage and mean fluorescence intensity; MFI) of co-stimulatory (CD80 and CD86) and MHC class molecules (MHC-I and MHC-II) in CD11 ${ }^{+}$cells were analyzed using flow cytometry. All data (dot plot and bar graphs) are representative of three independent experiments with similar results. Data represent the mean $\pm \mathrm{SD}$ (three samples for all experimental conditions); ${ }^{*} p<0.05,{ }^{* *} p<0.01$, or ${ }^{* * *} p<0.001$. SD; standard deviation.

Under the experimental condition illustrated in Figure 1, Ocs-P-treated BMDCs significantly increased the production of extracellular TNF- $\alpha$ and IL-12p70; however, BMDCs did not increase IL-10 levels, a potent anti-inflammatory immunosuppressive cytokine (Figure 2A). These results 
were confirmed by the analysis of intracellular cytokine levels using flow cytometry (Figure 2B). Furthermore, immature DCs show high ability for Ag uptake, whereas mature DCs lose their ability to take up Ags [26], indicating that the analysis of Ag uptake ability is a critical step to confirm DC maturation. In this study, we hypothesized that Ocs-P treatment can induce decreased Ag uptake ability in BMDCs. The functional change for Ag uptake induced by Ocs-P treatment in BMDCs was analyzed using FITC-labeled dextran. As expected, LPS (positive control)- and Ocs-P-treated BMDCs displayed significantly decreased cellular uptake levels of dextran (Figure 2C). Importantly, the expression of surface molecules and immunostimulatory cytokines (TNF- $\alpha$ and IL-12p70) in $1 \mu \mathrm{g} / \mathrm{mL}$ Ocs-P-treated DCs was similar or slightly higher than non-treated DCs, while dextran uptake levels was significantly reduced. These results indicate that $1 \mu \mathrm{g} / \mathrm{mL}$ Ocs-P also have potential to induce the maturation of DCs. However, to investigate the accurate assessment for Ocs-P-induced DC maturation, concentration of $100 \mu \mathrm{g} / \mathrm{mL}$ of Ocs-P was selected for further investigation. Thereafter, to confirm that Ocs-P-induced DC maturation is not caused by contamination of other soluble factors, protein (Ocs-P) denaturation was induced by heating at $100^{\circ} \mathrm{C}$ for $30 \mathrm{~min}$, and cells were subsequently treated. Therefore, heat denaturation of Ocs-P abrogated the ability of Ocs-P-induced DC maturation (Figure 2D; expression of surface molecules, Figure 2E; production of Th1 cytokines). We further analyzed the amount of endotoxin in the Ocs-P using the LAL assay. However, endotoxin content of Ocs-P was $<4 \mathrm{pg} / \mathrm{mL}(<0.1 \mathrm{EU} / \mathrm{mL})$, which indicated that maturation of DCs induced by Ocs-P was not due to contaminating endotoxins or LPS. These results, together with the potent ability to induce secretion of predominant Th1-polarizing cytokines and the expression of surface molecules, indicate that Ocs-P can induce phenotypic and functional maturation of DCs that generate Th1 and CTL responses.

A

B
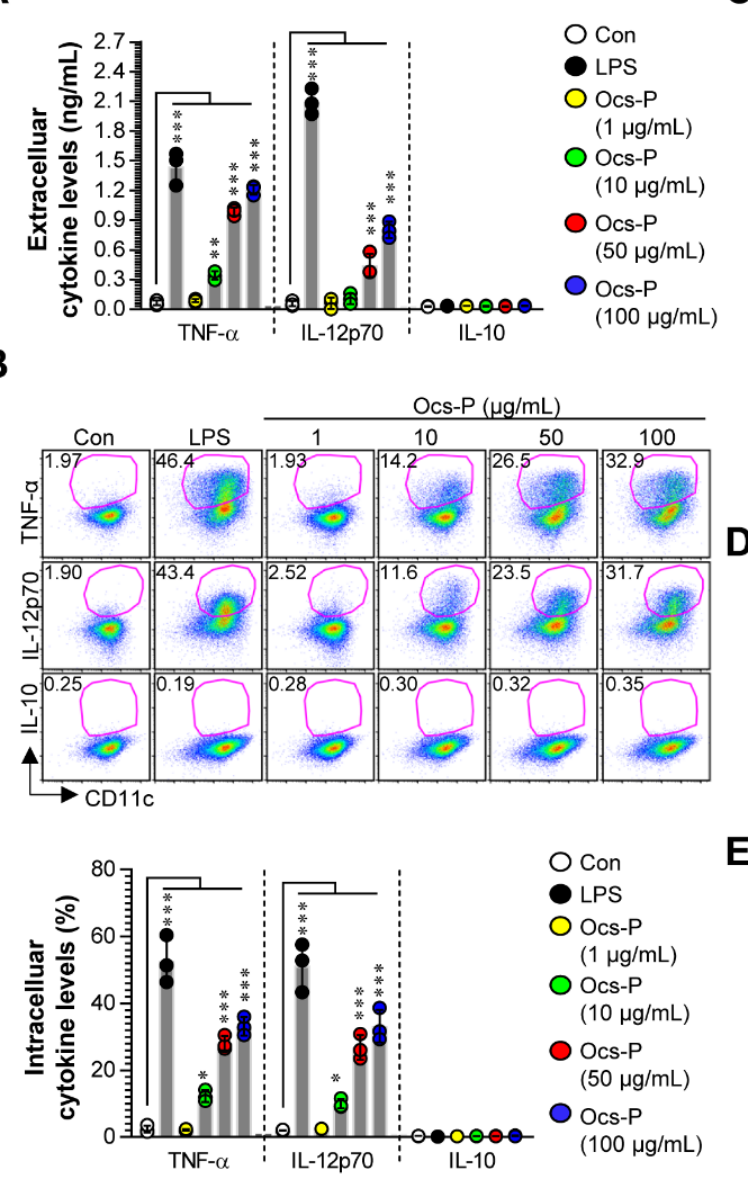

C
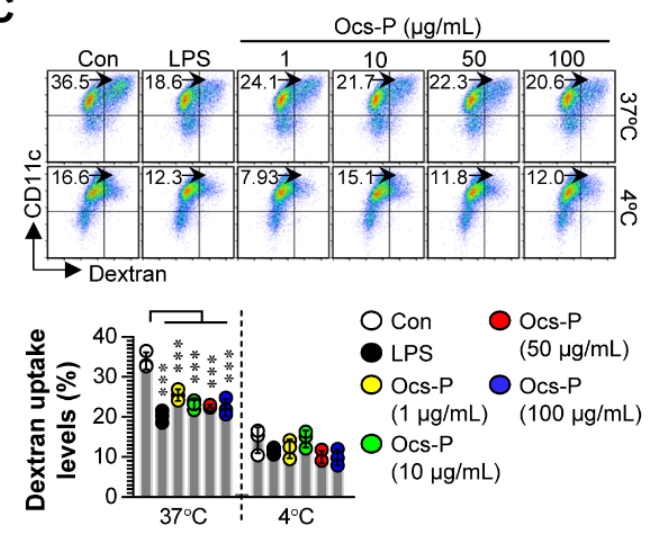

D
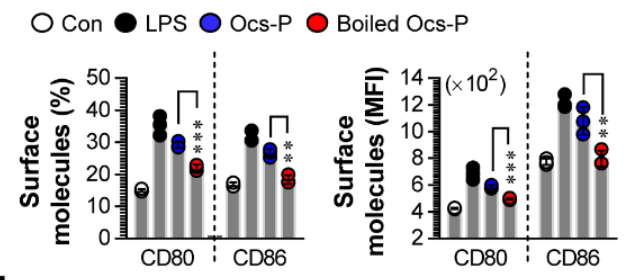

E

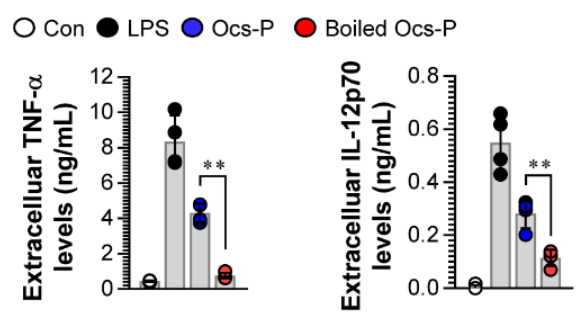

Figure 2. Analysis of cytokine profiles, antigen uptake ability, and surface molecules induced by Ocs-P or boiled Ocs-P treatment in in vitro cultured BMDCs. (A) Immature BMDCs were subjected to LPS 
(100 ng/mL) or Ocs-P (1 to $100 \mu \mathrm{g} / \mathrm{mL}$ ) for $20 \mathrm{~h}$ or no treatment (Con), and culture supernatants were harvested. Extracellular cytokine levels (TNF- $\alpha$, IL-12p70, IL-10) were analyzed using ELISA; (B) DCs were treated with LPS and Ocs-P in the presence of GolgiPlug for $8 \mathrm{~h}$ and stained with pan-DC marker (anti-CD11c) and intracellular cytokine detection antibodies (anti-TNF- $\alpha,-$ IL-12p70, and -IL-10). Intracellular cytokine levels were detected using flow cytometry; (C) Non- (Con), LPS-, and Ocs-P-treated DCs (treated for $20 \mathrm{~h}$ ) were incubated with FITC-dextran at $37^{\circ} \mathrm{C}$ and $4{ }^{\circ} \mathrm{C}$ for 40 min and stained with anti-CD11c Ab. Dextran uptake ability was measured using flow cytometry; (D,E) BMDCs were treated with LPS, Ocs-P $(100 \mu \mathrm{g} / \mathrm{mL})$, and boiled Ocs-P $(100 \mu \mathrm{g} / \mathrm{mL})$ for $20 \mathrm{~h}$. (D) Cells were stained with anti-CD11c, -CD80, and -CD86 Abs, and the expression levels of CD80 and CD86 in CD11 ${ }^{+}$cells were analyzed (E) Extracellular cytokine levels were analyzed in each culture supernatant using ELISA. All data (dot plots and bar graphs) are representative of three independent experiments with similar results. Data represent the mean \pm SD (three samples for all experimental conditions); ${ }^{*} p<0.05,{ }^{* *} p<0.01$, or ${ }^{* * *} p<0.001$. SD; standard deviation.

\subsection{Ocs-P Induces DC Maturation by Activating MAPK and NF-kB Signals}

We investigated the signaling molecular mechanism for DC maturation induced by Ocs-P treatment. We focused on the MAPK and NF-kB signaling pathways, as activation of these signals are important for inducing DC maturation [27]. Thus, we hypothesized that Ocs-P-induced DC maturation requires activation of MAPK and NF-kB signals. These signals were measured through western blotting after Ocs-P treatment at various time points. Notably, Ocs-P could activate MAPK and NF-kB signals by stimulating MAPK (ERK, JNK, p38) phosphorylation, IkB- $\alpha$ phosphorylation/degradation, and p65 nuclear translocation in DCs (Figure 3A,B). Thereafter, we analyzed whether the expression of surface molecules and production of Th1-polarizing cytokines induced by Ocs-P require MAPK and NF-kB signals. These experiments were performed in the presence of MAPK and NF-kB inhibitors. In Ocs-P-induced DC maturation, inhibition of MAPK and NF-kB signals showed significantly reduced surface molecule expression (Figure 3C; CD80, CD86, MHC-I, MHC-II) and Th1-polarizing cytokines (Figure 3D; TNF- $\alpha$, IL-12p70). These results indicate that MAPK and NF-kB signals are involved in Ocs-P-induced DC maturation.

A

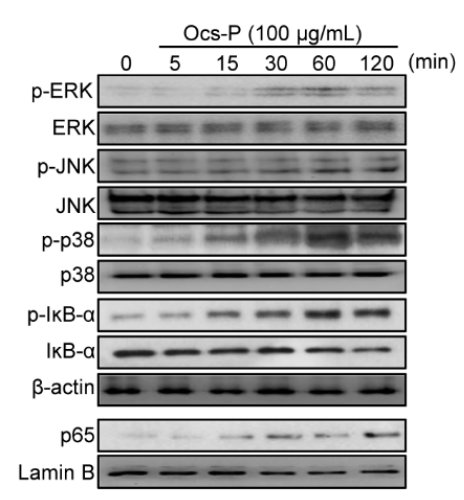

C

OCon OOcs-P

- LPS OOcs-P+U0126

O Ocs-P+SP600125 O Ocs-P+Bay11-7082

O Ocs-P+SB203580

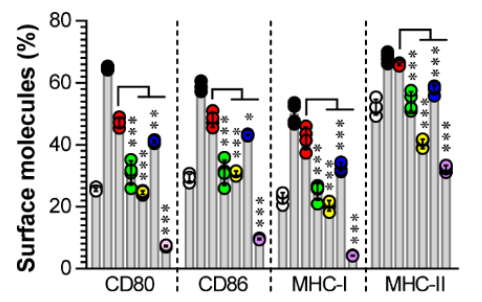

B
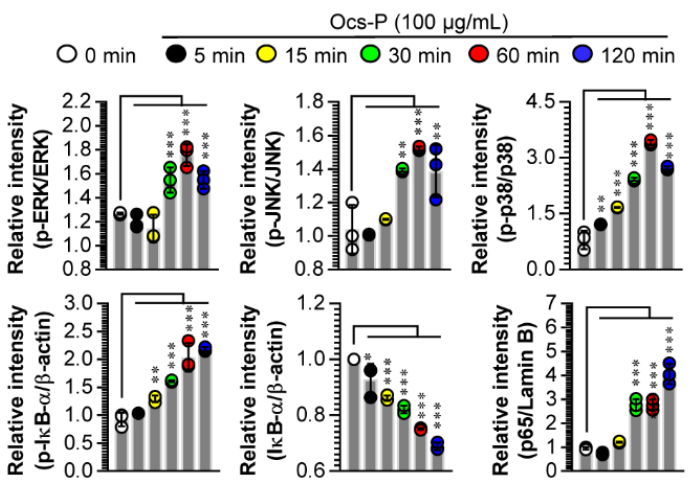

D

- LPS OOcs-P+U0126

O Ocs-P+SB203580 OOcs-P+
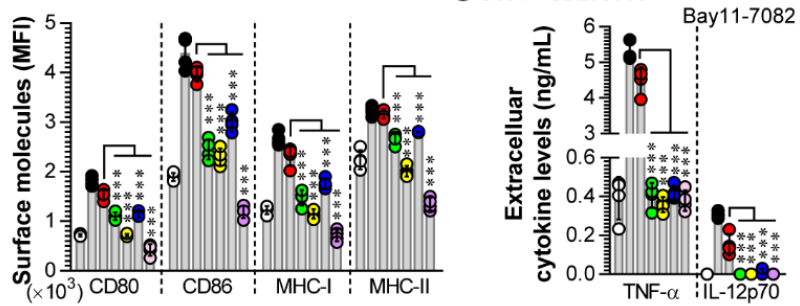

Figure 3. Effect of MAPK and NF-kB signals in Ocs-P-treated DC maturation. (A) BMDCs were stimulated with Ocs-P for 0 (non-treated DCs), 5, 15, 30, and $60 \mathrm{~min}$, and activation of Mitogen-activated 
protein kinase (MAPK) (phosphorylated extracellular-signal-regulated kinase (ERK), c-Jun N-terminal kinase (JNK), p38) and NF-kB (phosphorylated inhibitor kappa B-alpha (IkB- $\alpha$ ), IkB- $\alpha$ degradation, nuclear translocation of p65) signals were analyzed via western blotting; (B) The relative intensity for MAPK and NF-kB signals were normalized with $\beta$-actin or lamin B; (C,D) Cells were pretreated with inhibitors of each MAPK (ERK; U0126, JNK; SP600125, p38; SB203580) and NF-kB (Bay11-7082) signal for $2 \mathrm{~h}$ and subsequently stimulated with Ocs-P for $20 \mathrm{~h}$. (C) Analysis of surface molecules using flow cytometry. (D) Analysis of extracellular cytokines using ELISA. All data (western blot data and bar graphs) are representative of three independent experiments with similar results. Data represent the mean \pm SD (three samples for all experimental conditions); ${ }^{*} p<0.05,{ }^{* *} p<0.01$, or ${ }^{* * *} p<0.001$. SD; standard deviation.

\subsection{Ocs-P-stimulated DCs Induce T Cell Proliferation, Favor Th1 Polarization, and Activate Cytotoxic CD8 ${ }^{+}$T Cells}

Having established that Ocs-P induces DC maturation by MAPK and NF-kB activation, we evaluated whether Ocs-P-treated DCs can induce anticancer T cell immunity, such as Th1-type T cell immunity and CTL response. As shown in Figure $4 \mathrm{~A}, \mathrm{~B}, \mathrm{CD} 4^{+}$and $\mathrm{CD} 8^{+} \mathrm{T}$ cells co-cultured with LPS- and Ocs-P-treated DCs proliferated to a considerably greater extent (Figure 4A) and produced more Th1 cytokines (Figure 4B; IFN- $\gamma$, IL-2) than T cells co-cultured with non-treated DC (iDC), while IL-5 (Figure 4B; Th2 cytokine) levels showed no difference. Therefore, we subsequently analyzed in vivo CTL activity for Ocs-P-treated DCs (Figure 4C). To accomplish this, mice from each group were immunized with PBS, iDC, OVA $257-264$-treated DCs, and Ocs-P/OVA $257-264$-treated DCs. Five days after final immunization, mice were injected with mixed T cells (1:1 ratio; Cell Proliferation Dye ${ }^{\text {high }}$-stained $\mathrm{OVA}_{257-264}$-treated T cells and Cell Proliferation Dye ${ }^{\text {low }}$-stained non-treated T cells). For OVA-specific CTL response, Ocs-P/OVA $257-264$-treated DC-immunized groups showed a significantly reduced percentage (this phenomenon means induction of CTL activity) of Cell Proliferation Dye ${ }^{\text {high }}$-stained $\mathrm{OVA}_{257-264}$-treated $\mathrm{T}$ cells compared with $\mathrm{OVA}_{257-264}$-treated DC-immunized groups. These findings imply a strong possibility that Ocs-P could induce strong anticancer $\mathrm{T}$ cell immune responses.

A
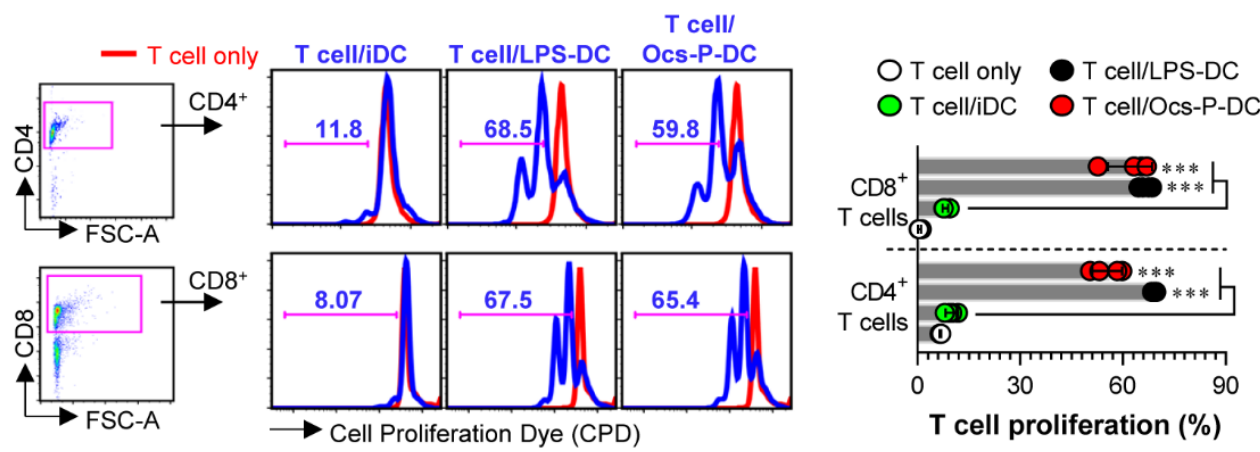

B

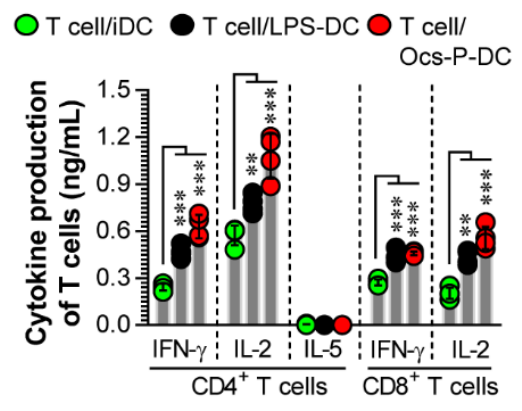

C

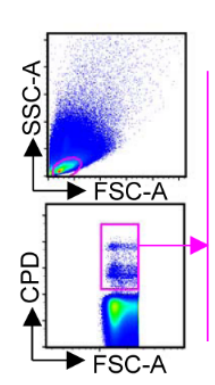

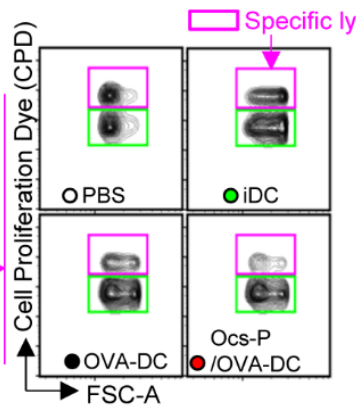

Figure 4. Analysis of proliferation, activation, and differentiation of T cells induced by Ocs-P-treated DCs. (A,B) Analysis of proliferation and differentiation of T cells induced by Ocs-P-treated DCs was measured using the allogenic MLR assay as described in the Materials and Methods. (A) Lymphocyte 
division using Cell Proliferation Dye (CPD)-stained $\mathrm{CD}^{+}$and $\mathrm{CD} 8^{+} \mathrm{T}$ cells co-cultured with each DC was analyzed using flow cytometry; (B) Type and activation (Th1: IFN- $\gamma$, IL-2 secretion; Th2: IL-5 secretion; activated CD8 ${ }^{+} \mathrm{T}$ cells: IFN- $\gamma$, IL-2 secretion) of T cells were evaluated in culture supernatants of T cells co-cultured with each DC. Histogram data and bar graphs are representative of three independent experiments with similar results. Data represent the mean $\pm \mathrm{SD}$ (four samples for all experimental conditions). $\mathrm{T}$ cell/iDC; $\mathrm{CD} 4^{+}$or $\mathrm{CD}^{+} \mathrm{T}$ cells co-cultured with non-treated DCs, T cell/LPS-DCs; $\mathrm{CD}^{+}{ }^{+}$or $\mathrm{CD}^{+}{ }^{+} \mathrm{T}$ cells co-cultured with LPS-treated DCs, T cell/Ocs-P-DCs; $\mathrm{CD} 4^{+}$or $\mathrm{CD}^{+} \mathrm{T}$ cells co-cultured with Ocs-P-treated DCs. (C) CTL activity was measured by OVA-specific killing effect induced by the injection of $\mathrm{CPD}^{\text {low }}$ - and $\mathrm{CPD}^{\text {high }}$-labeled splenocytes in mice immunized with non-treated DCs (iDC)-, OVA $257-264$-treated DCs (OVA-DC), and DCs (Ocs-P/OVA $257-264-\mathrm{DC}$ ) treated with Ocs-P and OVA $257-264$. Data are representative of two independent experiments with similar results. Data represent the mean $\pm \mathrm{SD}$ (five mice per group); ${ }^{* *} p<0.01$, or ${ }^{* * *} p<0.001$. SD; standard deviation.

\subsection{Ocs-P Inhibits Tumor Growth via Activation of Innate and Adaptive Immunity}

Based on the above results, we hypothesize three prediction results: (i) inhibitory effect of tumor growth by Ocs-P administration in tumor-bearing mice, (ii) DC maturation by Ocs-P administration during tumor progression, and (iii) induction of strong anticancer $\mathrm{T}$ cell immunity by Ocs-P administration in tumor-bearing mice. To explore this hypothesis, an animal study for anticancer effect and immunological contribution induced by Ocs-P administration was performed (Figure 5A). As expected, in the colon carcinoma-bearing mouse model, oral administration of Ocs-P exhibited significantly reduced tumor growth compared with PBS administration (Figure 5B). When mature phenotypes of lineage $\mathrm{CD}^{-} 1 \mathrm{c}^{+} \mathrm{MHC}-\mathrm{II}^{+}$splenic DCs in the spleens isolated from each group (normal group, PBS-administered tumor-bearing group, Ocs-P-administered tumor-bearing group) were assessed, PBS-administered tumor-bearing mice showed lower expression levels of surface molecules (CD80, CD86, MHC-I) in lineage ${ }^{-}$CD11 $\mathrm{c}^{+} \mathrm{MHC}-\mathrm{II}^{+}$splenic DCs compared with normal mice. Notably, Ocs-P administration restored the expression of CD80, CD86, and MHC-I in lineage-CD11 ${ }^{+} \mathrm{MHC}^{-} \mathrm{II}^{+}$ splenic DCs induced by tumor injection (Figure 5C).

A

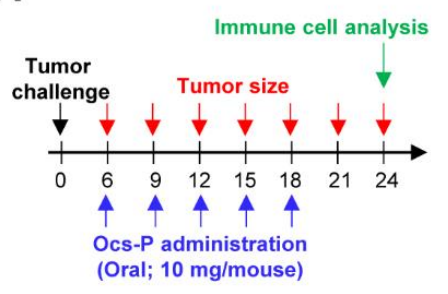

B

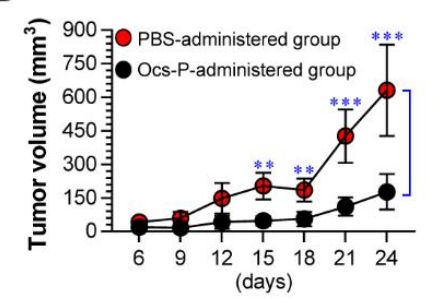

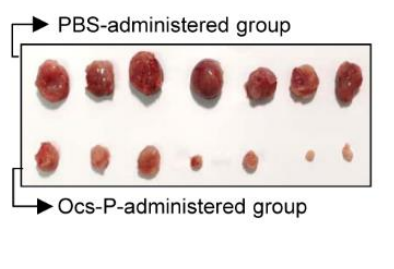

C
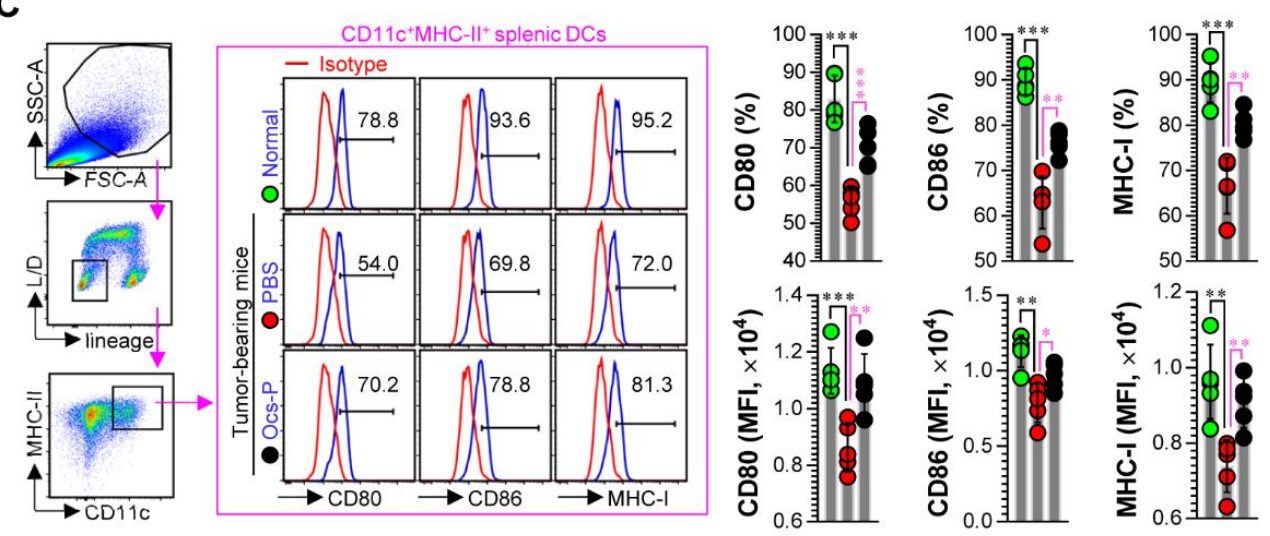

Figure 5. Analysis of protective efficiency and DC phenotypic alteration induced by Ocs-P administration in tumor-bearing mice. (A) Protocol for in vivo experiment (the effect of Ocs-P administration in CT26 
tumor-bearing mouse model); (B, left panel) Analysis of tumor growth at indicated time points after tumor challenge; (B, right panel) Photos of tumors induced by PBS and Ocs-P administration in CT26 tumor-bearing mice. Tumor size data represent the mean \pm SD (seven mice per group); (C) Expression of surface molecules (CD80, CD86, and MHC-I) in lineage-CD11c ${ }^{+} \mathrm{MHC}-\mathrm{II}^{+}$splenic DC from normal mice, PBS-administered tumor-bearing mice, and Ocs-P-administered tumor-bearing mice. All data are representative of two independent experiments with similar results. Bar graphs represent the mean $\pm \mathrm{SD}$ (five mice per group); ${ }^{*} p<0.05,{ }^{* *} p<0.01$, or ${ }^{* * *} p<0.001$. SD; standard deviation. $n$. s.; not significant.

Furthermore, we confirmed that Ocs-P induced T cell immunity in tumor-bearing mice. Notably, multifunctional $\mathrm{CD}^{+}$and $\mathrm{CD}^{+} \mathrm{T}$ cells capable of producing multiple Th1 cytokines (IFN- $\gamma, \mathrm{TNF}-\alpha$, IL-2) and expressing the degranulation marker (CD107a) play a critical role in cancer protection [28,29]. Thus, we further focused the functional phenotype for $\mathrm{CD}^{+}$and $\mathrm{CD} 8^{+} \mathrm{T}$ cell immune responses between the two groups (PBS-administered and Ocs-P-administered tumor-bearing group). To accomplish this, spleen cells from each group were evaluated for the frequency of the single, double, triple, or quadruple functional $\mathrm{CD}^{+}$(Figure 6A) and $\mathrm{CD}^{+} \mathrm{T}$ cells (Figure 7A) by flow cytometry using intracellular staining for multiple cytokines. As a result, $\mathrm{CD}^{+} \mathrm{T}$ cell response induced by oral administration of Ocs-P displays a high degree of multifunctionality with increased CD107a ${ }^{+} \mathrm{IFN}-\gamma^{+} \mathrm{IL}-2^{+} \mathrm{TNF}-\alpha^{+}$ (up to 1.5-fold), CD107a ${ }^{+}$IFN- $\gamma^{+}$IL-2 ${ }^{+}$(up to 1.4-fold)-, CD107a ${ }^{+}$IFN- $\gamma^{+}$TNF- $\alpha^{+}$(up to 1.7-fold)-, CD107a ${ }^{+}$IFN- $\gamma^{+}$(up to 1.6-fold)-, and IFN- $\gamma^{+}$TNF- $\alpha^{+}$(up to 1.3-fold)-producing T cells compared with the PBS-administered tumor-bearing group (Figure 6B).

A

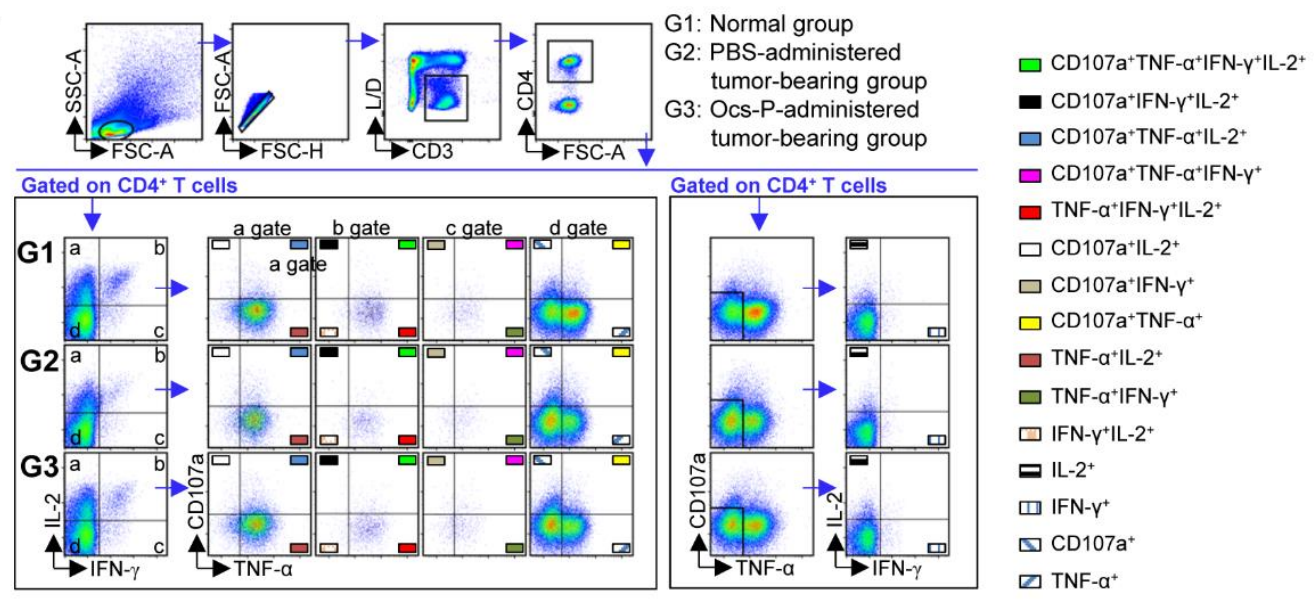

B

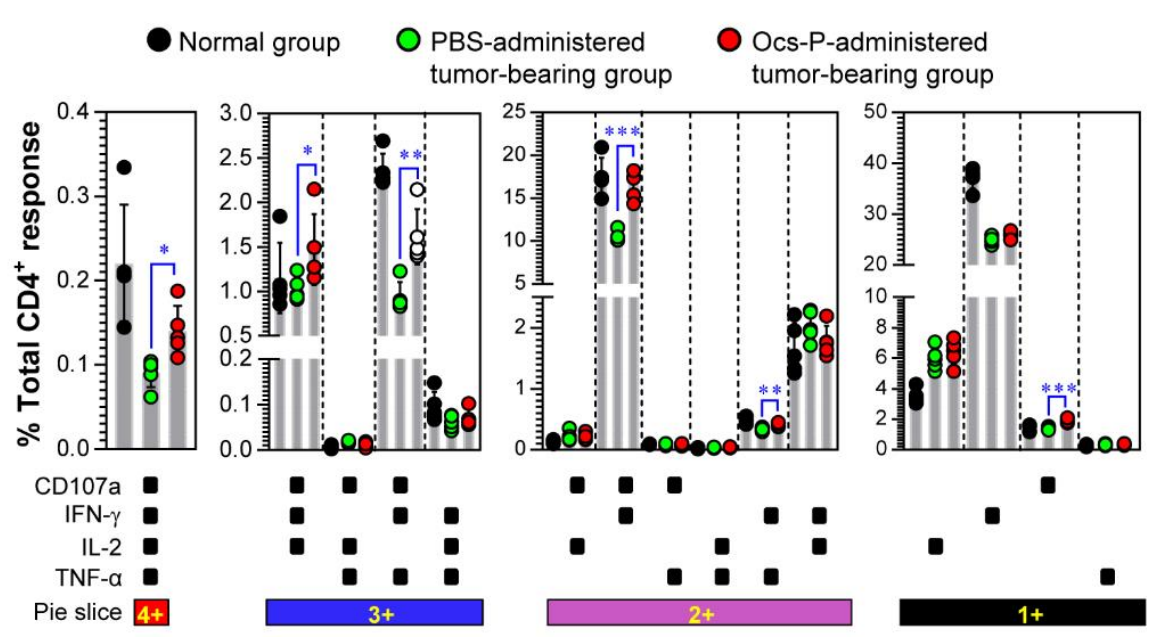

Figure 6. Analysis of multifunctional $\mathrm{CD}^{+} \mathrm{T}$ cell responses induced by Ocs-P administration in tumor-bearing mice. At $24 \mathrm{~d}$ after tumor challenge, single-cell suspensions of the spleens from each 
group (normal group, PBS-administered tumor-bearing group, and Ocs-P-administered tumor-bearing group) were isolated and treated with Cell Stimulation Cocktail (plus protein transport inhibitor) in the presence of anti-CD107a Ab for $4 \mathrm{~h}$. Thereafter, cells were stained with L/D, anti-CD3, -CD4, -IFN- $\gamma$, -IL-2, and -TNF- $\alpha$ Abs as described in the Materials and Methods. (A) Gating strategy for multifunctional $\mathrm{CD}^{+}{ }^{+} \mathrm{T}$ cells via flow cytometry analysis. Forward scatter area; FSC-A, forward scatter height; FSC-H, side scatter height; SSC-A; (B) The percentage of single, double, triple, or quadruple functional CD4 ${ }^{+}$ $\mathrm{T}$ cells in three groups are indicated in bar graphs. All data are representative of two independent experiments with similar results. Bar graphs represent the mean $\pm \mathrm{SD}$ (five mice per group); $p<0.05$, ** $p<0.01$, or *** $p<0.001$. SD; standard deviation.

A

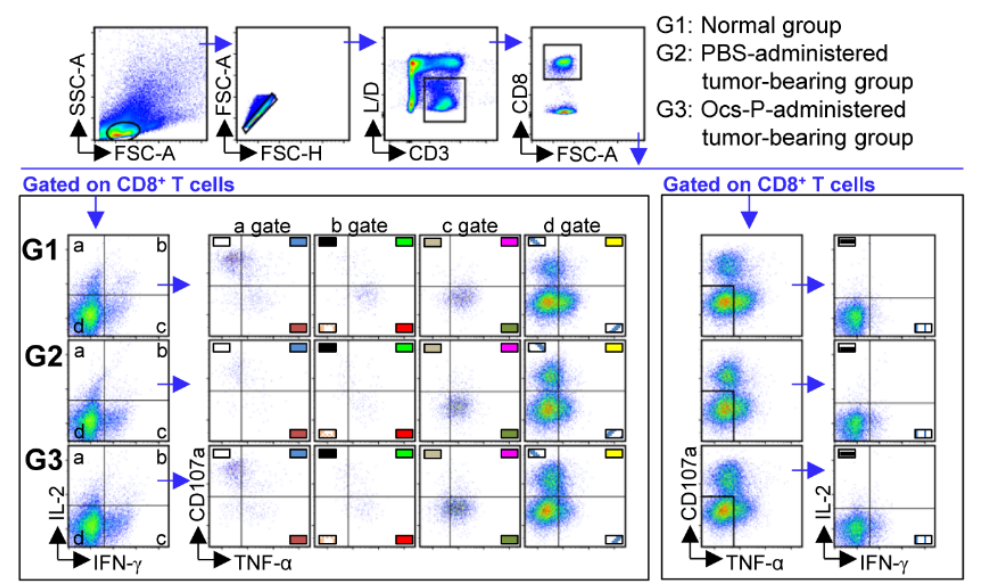

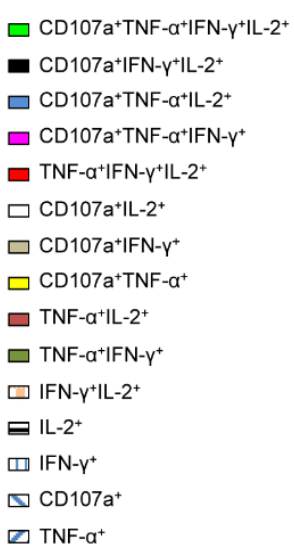

B

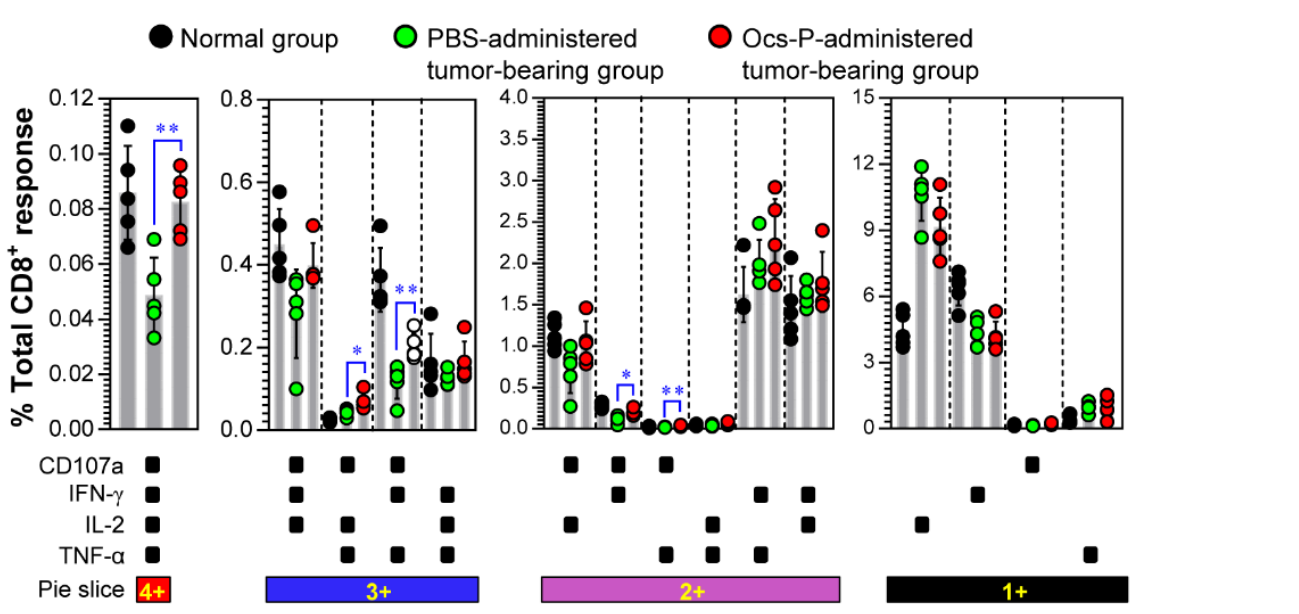

Figure 7. Analysis of multifunctional $\mathrm{CD}^{+} \mathrm{T}$ cell responses induced by Ocs-P administration in tumor-bearing mice. At $24 \mathrm{~d}$ after tumor challenge, single-cell suspensions of the spleens from each group (normal group, PBS-administered tumor-bearing group and Ocs-P-administered tumor-bearing group) were isolated, and treated with Cell Stimulation Cocktail (plus protein transport inhibitor) in the presence of anti-CD107a Ab for $4 \mathrm{~h}$. Thereafter, cells were stained with L/D, anti-CD3, -CD8, -IFN- $\gamma$, -IL-2, and -TNF- $\alpha$ Abs as described in the Materials and Methods. (A) Gating strategy for multifunctional $\mathrm{CD}^{+} \mathrm{T}$ cells by flow cytometry analysis; (B) The percentage of single, double, triple, or quadruple functional $\mathrm{CD}^{+} \mathrm{T}$ cells in three groups are indicated in bar graphs. All data are representative of two independent experiments with similar results. Bar graphs represent the mean \pm SD (five mice per group); ${ }^{*} p<0.05,{ }^{* *} p<0.01$. SD; standard deviation.

Thereafter, when $\mathrm{CD}^{+} \mathrm{T}$ cell responses were analyzed, Ocs-P-administered tumor-bearing group showed higher frequencies of CD107a $\mathrm{a}^{+} \mathrm{IFN}-\gamma^{+} \mathrm{IL}-2^{+} \mathrm{TNF}-\alpha^{+}$(up to 1.7-fold), CD107a $\mathrm{IL}^{+} 2^{+} \mathrm{TNF}-\alpha^{+}$ (up to 1.6-fold)-, CD107a ${ }^{+}$IFN- $\gamma^{+}$TNF- $\alpha^{+}$(up to 1.7-fold)-, CD107a $\mathrm{a}^{+}$IFN- $\gamma^{+}$(up to 1.8-fold)-, 
and CD107a+TNF- $\alpha^{+}$(up to 1.8-fold)-producing $\mathrm{T}$ cells compared with the PBS-administered tumor-bearing group (Figure 7B). Collectively, our results suggest that Ocs-P could improve DC maturation inhibited by cancer progression, and this DC maturation may contribute to the upregulation of multifunctional $\mathrm{CD}^{+}$and $\mathrm{CD}^{+} \mathrm{T}$ cells.

\section{Discussion}

This study aimed to investigate the immunological contribution of Ocs-P in DCs and showed that Ocs-P functionally converts immature DCs into immunogenic mature DCs with functional and phenotypic change that increases the production of Th1-polarizing cytokines and the expression of surface molecules by MAPK- and NF-kB-dependent signaling pathways. Additionally, these Ocs-P-stimulated mature DCs promoted proliferation and activation of naive $\mathrm{CD}^{+}{ }^{+}$and $\mathrm{CD}^{+} \mathrm{T}$ cells along with increased IFN- $\gamma$ and IL-2 production, suggesting the potential of Ocs-P in providing anticancer immunity.

In fact, several studies have suggested that successful therapy in the initiation, promotion, and progression stages of tumors rely on the ability of DCs, as effective and reliable DC maturation can initiate antitumor $\mathrm{T}$ cell immunity, including Th1 and activated CD8 ${ }^{+} \mathrm{T}$ cell responses (or CTL response) [30-32]. However, in tumor microenvironments, tumor-mediated soluble factors, such as cytokines (IL-10, IL-6, TGF- $\beta$ ), enzymes (indoleamine 2,3-dioxygenase, arginase), and lipid mediators (prostaglandins), impair the phenotypic and functional properties of DCs and skew their differentiation by bone marrow precursors toward immunosuppressive and tolerogenic DCs (or regulatory DCs) $[33,34]$. Eventually, these cells inhibit anticancer T cell immunity and thus stimulate tumor development and growth [35]. Therefore, to effectively control tumors, it is necessary to restore immunosuppressive DC function or eliminate tumor-mediated soluble factors.

Recently, phenotypes and properties of tumor-associated DCs have been extensively studied. DCs isolated from several tumor models and cancer patients were found to possess tolerogenic properties, such as low levels of co-stimulatory molecules (CD80, CD86) and low production of Th1-polarizing cytokine IL-12 [18,36,37]. Notably, we observed similar results in our in vivo experiment (Figure 5C). The expression levels of CD80, CD86, and MHC-I on CD11c ${ }^{+} \mathrm{MHC}-\mathrm{II}^{+}$splenic DCs from mice inoculated with murine colon carcinoma cells were lower when compared with normal mice. Notably, Ocs-P administration has been shown to inhibit tumor growth and restore expression of

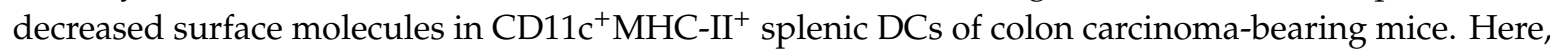
focused DCs are an extremely promising cell type for cancer immunotherapy [38]. Thus, while the functional role of DCs induced by Ocs-P administration for differentiation and activation of T cells requires more directed study, our results predicted that Ocs-P-mediated DCs may contribute to elicit robust antitumor $\mathrm{T}$ cell immunity in the progression stage of tumor growth.

As a component of the adaptive immune system, cytotoxic $\mathrm{CD}^{+} \mathrm{T}$ cells play a vital role in anticancer immunity by releasing cytotoxic granules and killing tumor cells $[39,40]$. Notably, a recent study has shown that multifunctional $\mathrm{CD}^{+} \mathrm{T}$ cells that simultaneously express Th1 cytokines and/or CD107a as a marker for cytotoxic granules have a greater protective effect than monofunctional CD8 ${ }^{+}$ $T$ cells in a DC-based vaccine study against metastatic melanoma [41]. In addition, there are several studies in preclinical and clinical settings showing that a higher frequency of multifunctional CD ${ }^{+}$ cells that produce IFN- $\gamma$, TNF- $\alpha$, CD107a, and/or IL-2 have been observed in various models of cancer immunotherapy, such as T cell therapy, antibody therapy, and vaccine therapy [41-45]. Notably, CD4 ${ }^{+}$ T cells are known to support survival and memory formation of tumor-specific multifunctional CD8 ${ }^{+}$ T cells $[46,47]$. Furthermore, multifunctional CD4 ${ }^{+}$CTLs, which have characteristics and functions similar to those of cytotoxic $\mathrm{CD}^{+} \mathrm{T}$ cells, play an important role in the fight against cancer $[28,39,48]$. In this regard, inducing multifunctional $\mathrm{CD} 4^{+}$and $\mathrm{CD} 8^{+} \mathrm{T}$ cells is critical to the success of various therapeutic cancer strategies. Thus, we finally evaluated the multifunctional capacity of $\mathrm{T}$ cells induced by Ocs-P administration in tumor-bearing mice. Interestingly, Ocs-P administration showed higher levels of multifunctional $\mathrm{CD}^{+}$and $\mathrm{CD}^{+} \mathrm{T}$ cells capable of expressing multiple cytokines. Collectively, 
our results suggest that Ocs-P can promote the antitumor effect by generating multifunctional $\mathrm{CD} 4^{+}$ and $\mathrm{CD} 8^{+} \mathrm{T}$ cells based on the restoration of tumor-associated DC maturation.

\section{Conclusions}

In summary, this study reports the immunological roles of Ocs-P in activation for DC maturation in vitro and the effect of Ocs-P as an immunostimulator for improvement of the anticancer immune response. The results revealed that Ocs-P promoted the expression of CD80, CD86, MHC-I, and MHC-II on DCs, along with the release of Th1-polarizing cytokines by activating MAPK and NF-kB signals. These Ocs-P-stimulated DCs activated the adaptive immune response by proliferation and differentiation of naive T cells into Th1 and activated cytotoxic CD8 ${ }^{+} \mathrm{T}$ cells. Notably, Ocs-P administration conferred strong anticancer $\mathrm{T}$ cell immunity (multifunctional $\mathrm{CD} 4^{+}$and $\mathrm{CD} 8^{+}$immune responses) and significant protection to mice that received colon carcinoma cells, suggesting that Ocs-P will be potentially useful in developing nutraceuticals to improve anticancer immunity. Nevertheless, the characterization and identification of novel immunogenic proteins contained in Ocs-P require further investigation. These additional studies may contribute to the development of effective immunological adjuvant targeted toward the treatment of infectious diseases (intracellular pathogens) and cancers.

Author Contributions: Conceptualization, W.S.K.; methodology, W.S.K., and E.-H.B.; formal analysis, W.S.K., J.M.H., and H.-Y.S.; investigation, W.S.K., J.M.H., H.S.S. and E.-B.B.; writing original draft preparation, W.S.K., and J.M.H.; writing review and editing, W.S.K.; supervision, E.-B.B.; project administration, E.-B.B. All authors have read and agreed to the published version of the manuscript.

Funding: This work was supported by the Basic Science Research Program through the National Research Foundation of Korea (NRF) funded by the Ministry of Science, ICT and Future Planning (NRF-2019R1C1C1002484).

Conflicts of Interest: The authors declare no conflict of interest.

\section{References}

1. Huis, A.V.; Itterbeeck, J.V.; Klunder, H.; Mertens, E.; Halloran, A.; Muir, G.; Vantomme, P. Edible Insects: Future Prospects for Food and Feed Security; FAO Forestry Paper; Food and Agriculture Organization of the United Nations: Rome, Italy, 2013.

2. Cerritos, R. Insects as food: An ecological, social and economical approach. CAB Rev. Perspect. Agric. Vet. Sci. Nutr. Nat. Resour. 2009, 4, 1-10. [CrossRef]

3. Berenbaum, M.R.; Eisner, T. Bugs' bugs. Science 2008, 322, 52-53. [CrossRef] [PubMed]

4. Hwang, J.; Kim, H.; Choe, J.Y. The Role of Eco-Friendly Edible Insect Restaurants in the Field of Sustainable Tourism. Int. J. Environ. Res. Public Health 2020, 17, 4064. [CrossRef] [PubMed]

5. Bukkens, S.G. The nutritional value of edible insects. Ecol. Food Nutr. 1997, 36, 287-319. [CrossRef]

6. Rumpold, B.A.; Schluter, O.K. Nutritional composition and safety aspects of edible insects. Mol. Nutr. Food Res. 2013, 57, 802-823. [CrossRef]

7. Jantzen da Silva Lucas, A.; Menegon de Oliveira, L.; da Rocha, M.; Prentice, C. Edible insects: An alternative of nutritional, functional and bioactive compounds. Food Chem. 2020, 311, 126022. [CrossRef]

8. Nongonierma, A.B.; FitzGerald, R.J. Unlocking the biological potential of proteins from edible insects through enzymatic hydrolysis: A review. Innov. Food Sci. Emerg. Technol. 2017, 43, 239-252. [CrossRef]

9. Kim, T.K.; Yong, H.I.; Kim, Y.B.; Kim, H.W.; Choi, Y.S. Edible Insects as a Protein Source: A Review of Public Perception, Processing Technology, and Research Trends. Food Sci. Anim. Resour. 2019, 39, 521-540. [CrossRef]

10. Chatsuwan, N.; Nalinanon, S.; Puechkamut, Y.; Lamsal, B.P.; Pinsirodom, P. Characteristics, functional properties, and antioxidant activities of water-soluble proteins extracted from grasshoppers, Patanga succincta and Chondracris roseapbrunner. J. Chem. 2018, 2018. [CrossRef]

11. Li, X.; Xie, H.; Chen, Y.; Lang, M.; Chen, Y.; Shi, L. Silkworm Pupa Protein Hydrolysate Induces Mitochondria-Dependent Apoptosis and S Phase Cell Cycle Arrest in Human Gastric Cancer SGC-7901 Cells. Int. J. Mol. Sci. 2018, 19, 1013. [CrossRef] 
12. Yu, W.; Ying, H.; Tong, F.; Zhang, C.; Quan, Y.; Zhang, Y. Protective effect of the silkworm protein 30Kc6 on human vascular endothelial cells damaged by oxidized low density lipoprotein (Ox-LDL). PLoS ONE 2013, 8, e68746. [CrossRef] [PubMed]

13. Dutta, P.; Sahu, R.K.; Dey, T.; Lahkar, M.D.; Manna, P.; Kalita, J. Beneficial role of insect-derived bioactive components against inflammation and its associated complications (colitis and arthritis) and cancer. Chem. Biol. Interact. 2019, 313, 108824. [CrossRef] [PubMed]

14. Kim, I.W.; Markkandan, K.; Lee, J.H.; Subramaniyam, S.; Yoo, S.; Park, J.; Hwang, J.S. Transcriptome Profiling and In Silico Analysis of the Antimicrobial Peptides of the Grasshopper Oxya chinensis sinuosa. J. Microbiol. Biotechnol. 2016, 26, 1863-1870. [CrossRef] [PubMed]

15. Tan, J.; Tian, Y.; Cai, R.; Yi, T.; Jin, D.; Guo, J. Antiproliferative and Proapoptotic Effects of a Protein Component Purified from Aspongopus chinensis Dallas on Cancer Cells In Vitro and In Vivo. Evid. Based Complement Altern. Med. 2019, 2019, 8934794. [CrossRef]

16. Kim, H.J.; Kang, S.J.; Kim, S.G.; Kim, J.E.; Koo, H.Y. Antioxidant activity and antimicrobial activity of the grasshopper, Oxya chinensis sinuosa. J. Sericultural Entomol. Sci. 2015, 53, 130-134. [CrossRef]

17. Lee, W.; Lee, H.; Kim, M.A.; Choi, J.; Kim, K.M.; Hwang, J.S.; Na, M.; Bae, J.S. Evaluation of novel factor Xa inhibitors from Oxya chinensis sinuosa with anti-platelet aggregation activity. Sci. Rep. 2017, 7, 1-13. [CrossRef]

18. Hossain, M.K.; Wall, K.A. Use of Dendritic Cell Receptors as Targets for Enhancing Anti-Cancer Immune Responses. Cancers (Basel) 2019, 11, 418. [CrossRef]

19. Kim, W.S.; Yoon, J.H.; Shin, M.K.; Shin, S.J. Infection of Dendritic Cells With Mycobacterium avium subspecies hominissuis Exhibits a Functionally Tolerogenic Phenotype in Response to Toll-Like Receptor Agonists via IL-10/Cox2/PGE2/EP2 Axis. Front. Microbiol. 2019, 10, 1795. [CrossRef]

20. Kim, W.S.; Kim, K.; Byun, E.B.; Song, H.Y.; Han, J.M.; Park, W.Y.; Yuk, J.M.; Byun, E.H. RM, a novel resveratrol derivative, attenuates inflammatory responses induced by lipopolysaccharide via selectively increasing the Tollip protein in macrophages: A partial mechanism with therapeutic potential in an inflammatory setting. Int. Immunopharmacol. 2020, 78, 106072. [CrossRef]

21. Burkholder, B.; Huang, R.Y.; Burgess, R.; Luo, S.; Jones, V.S.; Zhang, W.; Lv, Z.Q.; Gao, C.Y.; Wang, B.L.; Zhang, Y.M.; et al. Tumor-induced perturbations of cytokines and immune cell networks. Biochim. Biophys. Acta 2014, 1845, 182-201. [CrossRef]

22. Lutz, M.B. Induction of CD4(+) Regulatory and Polarized Effector/helper T Cells by Dendritic Cells. Immune Netw. 2016, 16, 13-25. [CrossRef] [PubMed]

23. Gardner, A.; Ruffell, B. Dendritic Cells and Cancer Immunity. Trends Immunol. 2016, 37, 855-865. [CrossRef] [PubMed]

24. Croft, M. The role of TNF superfamily members in T-cell function and diseases. Nat. Rev. Immunol. 2009, 9, 271-285. [CrossRef] [PubMed]

25. Rautajoki, K.J.; Kylaniemi, M.K.; Raghav, S.K.; Rao, K.; Lahesmaa, R. An insight into molecular mechanisms of human T helper cell differentiation. Ann. Med. 2008, 40, 322-335. [CrossRef] [PubMed]

26. Perreau, M.; Mennechet, F.; Serratrice, N.; Glasgow, J.N.; Curiel, D.T.; Wodrich, H.; Kremer, E.J. Contrasting effects of human, canine, and hybrid adenovirus vectors on the phenotypical and functional maturation of human dendritic cells: Implications for clinical efficacy. J. Virol. 2007, 81, 3272-3284. [CrossRef]

27. Nakahara, T.; Moroi, Y.; Uchi, H.; Furue, M. Differential role of MAPK signaling in human dendritic cell maturation and Th1/Th2 engagement. J. Dermatol. Sci. 2006, 42, 1-11. [CrossRef]

28. Takeuchi, A.; Saito, T. CD4 CTL, a Cytotoxic Subset of CD4(+) T Cells, Their Differentiation and Function. Front. Immunol. 2017, 8, 194. [CrossRef]

29. Chauchet, X.; Hannani, D.; Djebali, S.; Laurin, D.; Polack, B.; Marvel, J.; Buffat, L.; Toussaint, B.; Le Gouellec, A. Poly-functional and long-lasting anticancer immune response elicited by a safe attenuated Pseudomonas aeruginosa vector for antigens delivery. Mol. Ther. Oncolytics 2016, 3, 16033. [CrossRef]

30. Wylie, B.; Macri, C.; Mintern, J.D.; Waithman, J. Dendritic Cells and Cancer: From Biology to Therapeutic Intervention. Cancers (Basel) 2019, 11, 521. [CrossRef]

31. Palucka, K.; Banchereau, J. Dendritic-cell-based therapeutic cancer vaccines. Immunity 2013, 39, 38-48. [CrossRef]

32. Perez, C.R.; De Palma, M. Engineering dendritic cell vaccines to improve cancer immunotherapy. Nat. Commun. 2019, 10, 1-10. [CrossRef] 
33. Bellone, G.; Carbone, A.; Smirne, C.; Scirelli, T.; Buffolino, A.; Novarino, A.; Stacchini, A.; Bertetto, O.; Palestro, G.; Sorio, C.; et al. Cooperative induction of a tolerogenic dendritic cell phenotype by cytokines secreted by pancreatic carcinoma cells. J. Immunol. 2006, 177, 3448-3460. [CrossRef]

34. Ma, Y.; Shurin, G.V.; Gutkin, D.W.; Shurin, M.R. Tumor associated regulatory dendritic cells. Semin. Cancer Biol. 2012, 22, 298-306. [CrossRef]

35. Shurin, G.V.; Ma, Y.; Shurin, M.R. Immunosuppressive mechanisms of regulatory dendritic cells in cancer. Cancer Microenviron. 2013, 6, 159-167. [CrossRef]

36. Bauer, C.A.; Kim, E.Y.; Marangoni, F.; Carrizosa, E.; Claudio, N.M.; Mempel, T.R. Dynamic Treg interactions with intratumoral APCs promote local CTL dysfunction. J. Clin. Investig. 2014, 124, 2425-2440. [CrossRef]

37. Jia, J.; Wang, Z.; Li, X.; Wang, Z.; Wang, X. Morphological characteristics and co-stimulatory molecule (CD80, CD86, CD40) expression in tumor infiltrating dendritic cells in human endometrioid adenocarcinoma. Eur. J. Obstet. Gynecol. Reprod. Biol. 2012, 160, 223-227. [CrossRef]

38. Song, K.; Xu, L.; Zhang, W.; Cai, Y.; Jang, B.; Oh, J.; Jin, J.O. Laminarin promotes anti-cancer immunity by the maturation of dendritic cells. Oncotarget 2017, 8, 38554-38567. [CrossRef]

39. Durgeau, A.; Virk, Y.; Corgnac, S.; Mami-Chouaib, F. Recent Advances in Targeting CD8 T-Cell Immunity for More Effective Cancer Immunotherapy. Front. Immunol. 2018, 9, 14. [CrossRef]

40. Farhood, B.; Najafi, M.; Mortezaee, K. CD8(+) cytotoxic T lymphocytes in cancer immunotherapy: A review. J. Cell. Physiol. 2019, 234, 8509-8521. [CrossRef]

41. Wimmers, F.; Aarntzen, E.H.; Duiveman-deBoer, T.; Figdor, C.G.; Jacobs, J.F.; Tel, J.; de Vries, I.J. Long-lasting multifunctional CD8(+) T cell responses in end-stage melanoma patients can be induced by dendritic cell vaccination. Oncoimmunology 2016, 5, e1067745. [CrossRef]

42. Baumgaertner, P.; Jandus, C.; Rivals, J.P.; Derre, L.; Lovgren, T.; Baitsch, L.; Guillaume, P.; Luescher, I.F.; Berthod, G.; Matter, M.; et al. Vaccination-induced functional competence of circulating human tumor-specific CD8 T-cells. Int. J. Cancer 2012, 130, 2607-2617. [CrossRef]

43. Imai, N.; Ikeda, H.; Tawara, I.; Shiku, H. Tumor progression inhibits the induction of multifunctionality in adoptively transferred tumor-specific CD8+ T cells. Eur. J. Immunol. 2009, 39, 241-253. [CrossRef]

44. Imai, N.; Ikeda, H.; Tawara, I.; Wang, L.; Wang, L.; Nishikawa, H.; Kato, T.; Shiku, H. Glucocorticoid-induced tumor necrosis factor receptor stimulation enhances the multifunctionality of adoptively transferred tumor antigen-specific CD8+ T cells with tumor regression. Cancer Sci. 2009, 100, 1317-1325. [CrossRef]

45. Yuan, J.; Gnjatic, S.; Li, H.; Powel, S.; Gallardo, H.F.; Ritter, E.; Ku, G.Y.; Jungbluth, A.A.; Segal, N.H.; Rasalan, T.S.; et al. CTLA-4 blockade enhances polyfunctional NY-ESO-1 specific T cell responses in metastatic melanoma patients with clinical benefit. Proc. Natl. Acad. Sci. USA 2008, 105, 20410-20415. [CrossRef]

46. Shedlock, D.J.; Shen, H. Requirement for CD4 T cell help in generating functional CD8 T cell memory. Science 2003, 300, 337-339. [CrossRef]

47. Imai, N.; Tawara, I.; Yamane, M.; Muraoka, D.; Shiku, H.; Ikeda, H. CD4(+) T cells support polyfunctionality of cytotoxic CD8(+) T cells with memory potential in immunological control of tumor. Cancer Sci. 2020, 111, 1958-1968. [CrossRef]

48. Juno, J.A.; van Bockel, D.; Kent, S.J.; Kelleher, A.D.; Zaunders, J.J.; Munier, C.M. Cytotoxic CD4 T Cells-Friend or Foe during Viral Infection? Front. Immunol. 2017, 8, 19. [CrossRef]

Publisher's Note: MDPI stays neutral with regard to jurisdictional claims in published maps and institutional affiliations.

(C) 2020 by the authors. Licensee MDPI, Basel, Switzerland. This article is an open access article distributed under the terms and conditions of the Creative Commons Attribution (CC BY) license (http://creativecommons.org/licenses/by/4.0/). 